\title{
The effect of dietary 1,25-dihydroxycholecalciferol in preventing tibial dyschondroplasia in broilers fed on diets imbalanced in calcium and phosphorus
}

\author{
BY J. SARAH RENNIE, COLIN C. WHITEHEAD AND BARRY H. THORP \\ AFRC Institute of Animal Physiology and Genetics Research, Edinburgh Research Station, Roslin, \\ Midlothian EH25 9PS
}

(Received 25 November 1991-Accepted 8 May 1992)

\begin{abstract}
Three experiments were carried out to investigate the effects of supplemental dietary 1,25dihydroxycholecalciferol $\left(1,25(\mathrm{OH})_{2}\right.$ cholecalciferol) and a low dietary Ca:P ratio on the occurrence of tibial dyschondroplasia (TD) in 3-week-old broilers. Histopathology was used to diagnose TD. In the first experiment, feeding a diet containing $7.5 \mathrm{~g} \mathrm{Ca}$ and $7.6 \mathrm{~g} \mathrm{P} / \mathrm{kg}$ gave a higher incidence of TD than a control diet containing normal amounts of $\mathrm{Ca}$ and $\mathrm{P}(12$ and $6 \mathrm{~g} / \mathrm{kg}$ respectively). Increasing the dietary supplement of cholecalciferol in the imbalanced diet prevented rickets but did not decrease the incidence of TD. In the second experiment, supplementing the imbalanced diet with $10 \mu \mathrm{g}$ $1,25(\mathrm{OH})_{2}$ cholecaleiferol $/ \mathrm{kg}$ prevented TD completely but also gave a slight growth depression. In the third experiment the imbalanced diet was supplemented with $0,25,5$ or $10 \mu \mathrm{g} 1,25(\mathrm{OH})_{2}$ cholecalciferol $/ \mathrm{kg}$. The supplement of $2.5 \mu \mathrm{g} / \mathrm{kg}$ depressed and the higher supplements prevented the occurrence of TD, this time without a growth depression. Feeding the $10 \mu \mathrm{g} / \mathrm{kg}$ supplement for the first week only did not prevent TD. Plasma total $\mathrm{Ca}$, inorganic $\mathrm{P}$ and alkaline phosphatase (EC 3.1.3.1) were unaffected by diet but $1,25(\mathrm{OH})_{2}$ cholecalciferol was higher on the imbalanced than on the control diet. Supplementation of the imbalanced diet with $1,25(\mathrm{OH})_{2}$, cholecalciferol did not increase plasma levels. It is concluded that $1,25(\mathrm{OH})_{2}$ cholecalciferol is exerting a powerful biological effect in this model of $\mathrm{TD}$, but the mechanism is unclear.
\end{abstract}

Tibial dyschondroplasia: Cholecalciferol: $1,25(\mathrm{OH})_{2}$ cholecalciferol: Calcium-phosphorus balance: Broilers

Tibial dyschondroplasia (TD) is a well-recognized disorder of rapidly growing broilers, first described by Leach \& Nesheim (1965). TD affects the long bones, particularly the proximal tibiotarsus (PTT), and is characterized by the presence there of an avascular plug of cartilage. If the lesion is large, affected birds may become lame due to weakening, bowing or fracture of the PTT (Lynch et al. 1991). Less severely affected birds show thickening of the growth plate. Estimates of clinically affected birds are as high as $10 \%$ and many more birds may be sub-clinically affected.

Histologically the lesion consists of a mass of pre-hypertrophied chondrocytes, due to a failure, for as yet unknown reasons, of the normal sequence of chondrocyte differentiation through proliferating, hypertrophying and calcifying stages (Farquarson et al. 1991).

A high incidence of TD can be induced experimentally in a number of ways: for example, feeding diets with an altered cation:anion ratio or acid-base balance (Leach \& Nesheim, 1972; Halley et al. 1987), fusarochromanone administration, or by feeding certain organic sulphur compounds (Vargas et al. 1983; Veltmann et al. 1985; Edwards, 1987). Edwards \& Veltmann (1983) reported that feeding diets imbalanced in $\mathrm{Ca}-\mathrm{P}$ could induce a high 
incidence of TD as assessed by sectioning of bone extremities and gross examination of the growth plate. However, Riddell \& Pass (1987), using histological techniques, found that chickens fed on diets containing high concentrations of $\mathrm{P}$ developed thickened growth plates identical to those seen in Ca-deficiency rickets before the development of typical TD.

An involvement of cholecalciferol metabolites in TD has been reported (Edwards, 1989, 1990). Using basal diets low in $\mathrm{Ca}(7.5 \mathrm{~g} / \mathrm{kg})$ and high in $\mathrm{P}(7.6 \mathrm{~g} / \mathrm{kg})$, the addition of $1,25-$ dihydroxycholecalciferol $\left(1,25(\mathrm{OH})_{2}\right.$ cholecalciferol $)$ to a diet containing supplemental cholecalciferol in the presence and absence of disulfiram was found to result in a considerable increase in bone ash and a decreased incidence and severity of TD. However, in none of these experiments was this or any other metabolite of cholecalciferol found to prevent TD.

In these studies (Edwards, 1989, 1990) the occurrence of TD was assessed by visual examination of slices of PTT and identification of thickening of the growth plate. However, naked eye identification of TD is not so reliable as histopathological methods. This is because thickening of the growth plate can occur in the absence of cellular changes characteristic of TD (Thorp et al. 1991). Visual identification of TD lesions would be complicated further if rickets were also induced by the feeding of $\mathrm{Ca}-\mathrm{P}$ imbalanced diets, as rickets will also cause thickening of the growth plate.

The aim of the present study was to carry out a detailed histological investigation of the effects on feeding $1,25(\mathrm{OH})_{2}$ cholecalciferol on the occurrence of TD and rickets in young broilers fed on diets containing an imbalance of $\mathrm{Ca}$ and $\mathrm{P}$. Diagnosis of growth plate lesions was based on histopathology and biochemical characteristics of birds were also assessed.

\section{MATERIALS AND METHODS}

\section{Birds and husbandry}

Three experiments were conducted using groups of 1-d-old broiler chicks (Cobb strain; H. Morrison, Duns, Berwickshire) reared to 3 weeks of age in wire-floored electricallyheated brooder units. Food and water were available $a d$ lib. and diets, based on wheat and soya-bean meal, were either a control diet calculated to contain $(\mathrm{g} / \mathrm{kg}) \mathrm{Ca} 12, \mathrm{P}$, or a TDinducing diet calculated to contain $(\mathrm{g} / \mathrm{kg}) \mathrm{Ca} 7.5$ and $\mathrm{P} 7.6$ (Table 1). The TD-inducing diet was supplemented with various amounts of $1,25(\mathrm{OH})_{2}$ cholecalciferol, $0 \cdot 2 \mathrm{~g} / \mathrm{kg}$ in a stable matrix, kindly donated by Dr H. Weiser, Hoffmann-La Roche, Basle.

The aim of Expt 1 was to confirm, using histology, that diets imbalanced in $\mathrm{Ca}-\mathrm{P}$ could induce a high incidence of TD, and to test the effects of giving birds extra cholecalciferol. Three groups of birds were used, the first receiving the control diet and the second and third groups receiving the TD-inducing diet containing either 25 or $75 \mu \mathrm{g}$ cholecalciferol $/ \mathrm{kg}$.

Expt 2 assessed the effects of dietary supplementation of the TD-inducing diet with $1,25(\mathrm{OH})_{2}$ cholecalciferol. Three groups were again used, the first receiving the control diet, the second the TD-inducing diet, and the third the TD-inducing diet containing $10 \mu \mathrm{g}$ added $1,25(\mathrm{OH})_{2}$ cholecalciferol $/ \mathrm{kg}$.

Expt 3 assessed the effects of supplementing the TD-inducing diet with various amounts of $1,25(\mathrm{OH})_{2}$ cholecalciferol, and consisted of a control group and four experimental groups receiving the TD-inducing diet supplemented with either $0,2 \cdot 5,5$, or $10 \mu \mathrm{g} 1,25(\mathrm{OH})_{2}$ cholecalciferol $/ \mathrm{kg}$. A further group was fed the last diet up to $7 \mathrm{~d}$ of age before being transferred to the unsupplemented TD-inducing diet.

At 3 weeks of age birds were weighed and blood samples were taken from the wing vein of ten to fifteen birds per treatment, using heparin as anticoagulant. Plasma was separated and stored at $-20^{\circ}$ until it could be analysed. After blood sampling, all birds were killed by cervical dislocation and the PTT was examined and scored visually for growth plate 
Table 1. Composition of experimental diets $(\mathrm{g} / \mathrm{kg})$

\begin{tabular}{lcc}
\hline Ingredient & Control diet & Imbalanced diet \\
\hline Wheat & 559 & 563 \\
Soya-bean meal & 350 & 350 \\
Vegetable oil & 45 & 50 \\
Limestone & 13 & -5 \\
Dicalcium phosphate & 21 & 25 \\
Salt & 4 & 4 \\
Methionine & 2 & 2 \\
Lysine & 4 & 4 \\
Vitamin and mineral supplement* & 12 & 7.5 \\
Calculated analyses (g/kg) & 6 & 7.6 \\
Ca & & \\
P & & \\
\hline
\end{tabular}

* Provided (mg/kg diet): retinol $1376 \mu \mathrm{g}$, cholecalciferol $25 \mu \mathrm{g}, \alpha$-tocopherol 10 , menadione $1 \cdot 3$, thiamine $1 \cdot 3$, ribofavin $3 \cdot 3$, pyridoxine $1 \cdot 7$, cyanocobalamin $0 \cdot 6 \mu \mathrm{g}$, folic acid $0 \cdot 7$, biotin $267 \mu \mathrm{g}$, pantothenic acid $5 \cdot 3$, nicotinic acid $23 \cdot 3$, zinc 40 , copper $2 \cdot 9$, iodine $320 \mu \mathrm{g}$, iron 64 , manganese 80 , selenium $120 \mu \mathrm{g}$.

thickening. Sections of PTT were taken for histological examination to confirm TD and to characterize growth plate pathology.

\section{Laboratory procedures}

Total Ca, inorganic phosphate and alkaline phosphatase (EC 3.1.3.1) were measured using Wako kits (Alpha Laboratories, Eastleigh, Hants.) adapted for use with a platereader (Titertek Twin-Reader Plus; ICN, High Wycombe, Bucks.). Total Ca was measured in undiluted plasma, using $4 \mu \mathrm{l}$ plasma, $200 \mu \mathrm{l}$ buffer and $20 \mu \mathrm{l}$ colour reagent. A standard curve was prepared over the range $0-5 \mathrm{~mm}$ by dilution with extra-pure water (Millipore, Watford, Herts.) of standards provided with the kit. Samples were read after $20 \mathrm{~min}$ at $560 \mathrm{~nm}$. Inorganic phosphate was also measured in undiluted plasma, using $5 \mu \mathrm{l}$ plasma and $125 \mu \mathrm{l}$ mixed colour reagent. A standard curve was again constructed by dilution of standards provided with the kit over the range $0-100 \mathrm{mg} / 1$, and samples read after $20 \mathrm{~min}$ at $690 \mathrm{~nm}$. Alkaline phosphatase was measured in plasma diluted eighty times with extrapure water. Samples were kept on ice until they could be assayed. A standard curve was prepared by diluting $5 \mathrm{~mm}$ - -nitrophenol (Sigma, Poole, Dorset) in assay buffer to give a range of standards from 0 to $62.5 \mu \mathrm{M}$. Enzyme activity was measured by adding $10 \mu \mathrm{l}$ diluted plasma to $250 \mu 1$ substrate, and measuring absorbance at $405 \mathrm{~nm}$ for $10 \mathrm{~min}$. The mean change in absorbance per min was calculated and related to $p$-nitrophenol concentration. Alkaline phosphatase activity was calculated after correction for dilution, and expressed as units $(\mathrm{U}) .1,25(\mathrm{OH})_{2}$ cholecalciferol was measured in plasma using an Incstar kit (Incstar Ltd, Wokingham, Berks.).

Samples of PTT were fixed in buffered neutral formalin before decalcification in formic acid-formalin. Paraffin embedded sections were then prepared and stained with haematoxylin and eosin and examined. TD was diagnosed when characteristic changes to the chondrocytes of the proliferating, pre-hypertrophied and hypertrophied zones were seen, including accumulation of avascular matrix and degenerative changes in cytoplasm and nuclei. Rickets was diagnosed where changes in the growth plate included a widening of the proliferating zone and disturbances in vascularity within the growth plate (Lacey \& Huffer, 1982). 


\section{Statistical analyses}

Data were analysed by analysis of variance using Genstat statistical program.

\section{RESULTS}

The results from the first experiment confirm that feeding diets imbalanced in $\mathrm{Ca}$ and $\mathrm{P}$ to birds can induce a high incidence of TD (Table 2). The control group had a $14 \%$ incidence of TD, as assessed histologically, compared with a $21 \%$ incidence of TD and a $14 \%$ incidence of rickets in the group fed on the imbalanced diet containing $25 \mu \mathrm{g}$ cholecalciferol $/ \mathrm{kg}$, and a $46 \%$ incidence of TD and $0 \%$ incidence of rickets in the group fed on the imbalanced diet containing $75 \mu \mathrm{g}$ cholecalciferol $/ \mathrm{kg}$. There were no significant differences between treatments in bird weights, or between plasma $\mathrm{Ca}, \mathrm{P}$ or $1,25(\mathrm{OH})_{2}$ cholecalciferol concentrations. Alkaline phosphatase measurements were unsuccessful in the first experiment as the samples were not sufficiently diluted.

The second experiment showed that addition of $1,25(\mathrm{OH})_{2}$ cholecalciferol to a diet imbalanced in $\mathrm{Ca}$ and $\mathrm{P}$ can reduce the incidence of TD. The control group had a $29 \%$ incidence of TD compared with $19 \%$ in the group fed on the imbalanced diet. The incidence dropped to zero in the group fed on the imbalanced diet supplemented with $10 \mu \mathrm{g}$ $1,25(\mathrm{OH})_{2}$ cholecalciferol $/ \mathrm{kg}$. There was a significant difference in body weights between treatments, with the group receiving $1,25(\mathrm{OH})_{2}$ cholecalciferol having a significantly lower mean body weight than birds on the other two treatments. Again, there were no significant differences in plasma $\mathrm{Ca}, \mathrm{P}$ or alkaline phosphatase between treatments.

The third experiment showed that the response to dietary $1,25(\mathrm{OH})_{2}$ cholecalciferol is influenced by dose, in that the group receiving no $1,25(\mathrm{OH})_{2}$ cholecalciferol had a $36 \%$ incidence of TD, and the groups receiving $2 \cdot 5,5$, or $10 \mu \mathrm{g} / \mathrm{kg}$ had 19,0 , and $0 \%$ incidences respectively. In the present experiment there were no significant differences in body weights between treatments, although there was a trend towards lower body weight at the higher levels of supplementation of 5 and $10 \mu \mathrm{g} 1,25(\mathrm{OH})_{2}$ cholecalciferol $/ \mathrm{kg}$. There were no significant differences in plasma $\mathrm{Ca}, \mathrm{P}$ or alkaline phosphatase between treatments, although there was a trend towards hypercalcaemia with increasing dietary $1,25(\mathrm{OH})_{2}$ cholecalciferol. Feeding a diet imbalanced in $\mathrm{Ca}$ and $\mathrm{P}$ significantly increased mean circulating $1,25(\mathrm{OH})_{2}$ cholecalciferol levels in Expt 3 (although not in Expt 1) from 40 to $65 \mathrm{pg} / \mathrm{mI}$. Concentrations increased from a mean of $49 \mathrm{pg} / \mathrm{ml}$ in birds receiving $2.5 \mu \mathrm{g} 1,25(\mathrm{OH})_{2}$ cholecalciferol $/ \mathrm{kg}$, to a mean of $67 \mathrm{pg} / \mathrm{ml}$ in birds receiving $10 \mu \mathrm{g} 1,25(\mathrm{OH})_{2}$ cholecalciferol/kg.

\section{DISCUSSION}

These experimental results demonstrate that dietary supplementation with $1,25(\mathrm{OH})_{2}$ cholecalciferol can prevent the occurrence of TD in broilers fed on a diet imbalanced in $\mathrm{Ca}$ and P. The present study extends the observations of Edwards $(1989,1990)$ who demonstrated in several experiments substantial decreases in the incidence of TD after dietary supplementation with this metabolite. The observations of complete prevention of TD at the higher supplementation rates in the present study are perhaps the result of the use of histology to make a specific diagnosis of TD in the presence of other growth plate abnormalities, including rickets, which were also found to occur with the experimental diets used.

The first experiment confirmed that the use of a diet imbalanced in $\mathrm{Ca}$ and $\mathrm{P}$ and containing $25 \mu \mathrm{g}$ cholecalciferol $/ \mathrm{kg}$ could give a higher incidence of TD than a control diet containing normal amounts of $\mathrm{Ca}$, although this was not always the case in later experiments. That TD is not caused by a dietary deficiency of cholecalciferol per se was 


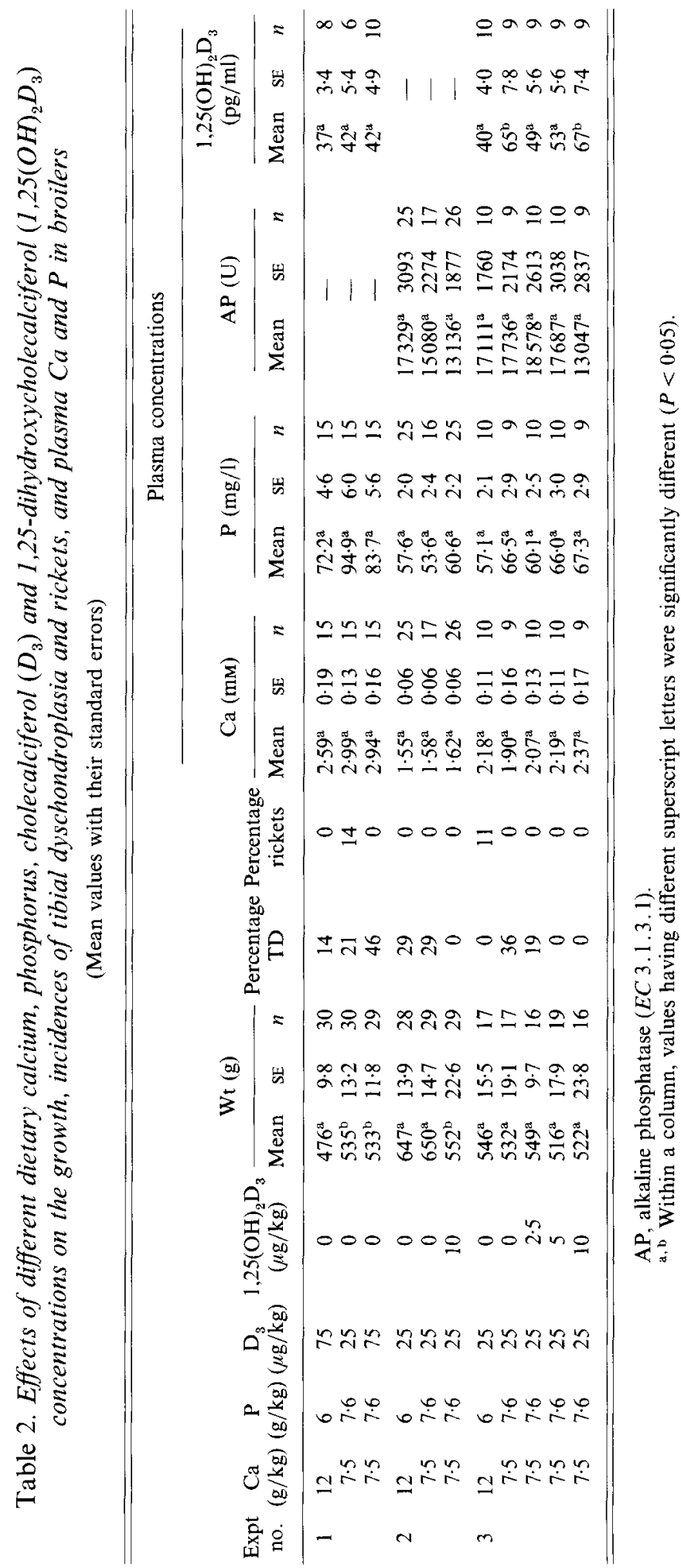


demonstrated by the fact that supplementation of the imbalanced diet to give a total cholecalciferol content of $75 \mu \mathrm{g} / \mathrm{kg}$ did not reduce the incidence of $\mathrm{TD}$, although it did prevent rickets.

The second experiment showed that a supplement of $10 \mu \mathrm{g} 1,25(\mathrm{OH})_{2}$ cholecalciferol $/ \mathrm{kg}$ could prevent the TD induced in this model. However, there was a significant depression of body weight with this diet, and a lower rate of growth is known to be associated with a decreased incidence of TD (Huff, 1980). In broiler chicks fed ad lib., growth accelerates rapidly from 2 weeks of age, with maximum allometric growth in the PTT occurring between 2 and 3 weeks of age (Thorp, 1988). Therefore, during this crucial period, any factor reducing growth rate will also reduce chondrocyte differentiation and, therefore, the likelihood of TD. The toxic effects of cholecalciferol metabolites were considered as a cause of the lowered body weight in this group, but as this result was not duplicated in the third experiment it was felt to be due instead to a factor outwith the experiment. The standard error of the mean for body weight was much higher in this group compared with other treatments.

The third experiment showed that a lower dose was also effective in reducing the incidence and severity of TD, and that dietary contents of 5 and $10 \mu \mathrm{g} / \mathrm{kg}$ were effective in preventing TD. In this experiment there was no significant growth depression at the higher supplemental levels. Plasma $\mathrm{P}$ and alkaline phosphatase were unaffected by supplementation whereas plasma $\mathrm{Ca}$ tended to be elevated, although the changes were not statistically significant. Circulating concentrations of $1,25(\mathrm{OH})_{2}$ cholecalciferol were elevated among birds given the TD-inducing diet compared with the control diet, but did not show any obvious response to dietary supplementation of the TD-inducing diet with $1,25(\mathrm{OH})_{2}$ cholecalciferol. It is well known that $\mathrm{Ca}$ deficiency increases the renal synthesis of $1,25(\mathrm{OH})_{2}$ cholecalciferol (Cancela et al. 1988) and in a recent study (Goff et al. 1990) circulating concentrations achieved after dietary restriction were comparable with those seen after injection of $1,25(\mathrm{OH})_{2}$ cholecalciferol, both being approximately eight times normal. In the present study $1,25(\mathrm{OH})_{2}$ cholecalciferol was administered orally. Its efficiency of absorption is not known, but absorption must have occurred in view of the profound effect on the incidence of TD. However, plasma concentrations of $1,25(\mathrm{OH})_{2}$ cholecalciferol are apparently not related to the development of TD.

It was also of interest in the third experiment that supplementation with $10 \mu \mathrm{g}$ $1,25(\mathrm{OH})_{2}$ cholecalciferol $/ \mathrm{kg}$ for the first week after hatching only did not prevent TD. This implies that supplementation is needed over the whole period when rapid bone growth is likely to make the growth plate more susceptible to TD. It also suggests that the problem does not originate at the breeder level, with inadequate carryover of cholecalciferol and its metabolites to the hatching chick.

It is clear from the experimental results that $1,25(\mathrm{OH})_{2}$ cholecalciferol is exerting a powerful biological effect in this TD model. In vitro studies have demonstrated receptors for $1,25(\mathrm{OH})_{2}$ cholecalciferol on chondrocytes (Suda et al. 1985) and the metabolite has been shown to have a powerful inhibitory effect on cell proliferation and a stimulatory effect on cell differentiation in chondrocytes derived from embryonic chicken caudal sterna (Gerstenfeld et al. 1990). A basis for the involvement of $1,25(\mathrm{OH})_{2}$ cholecalciferol, therefore, exists in this model of TD, either related to the supply of the metabolite to the chondrocyte and/or its effects on cellular activity. Soares et al. (1990) found a trend towards reduced numbers of $1,25(\mathrm{OH})_{2}$ cholecalciferol receptors in growth plate and intestine of TD-affected birds, but normal affinity for the hormone, as measured by Scatchard analysis. However, it is known from human studies (Marx, 1989) that defects related to cholecalciferol metabolism are complex, and may occur at every stage of the hormone acting on its target cell, from locating its receptor to binding to the nuclear DNA. 
It is also possible that the observed response to $1,25(\mathrm{OH})_{2}$ cholecalciferol is mediated through a further metabolite of the hormone.

The role of $1,25(\mathrm{OH})_{2}$ cholecalciferol in preventing TD in this model is as yet uncertain, and its significance in field cases can only be the subject of speculation. Further in vitro and in vivo studies are necessary to elucidate the mechanism by which broilers develop TD, and to clarify the role of cholecalciferol metabolism in the occurrence of this important condition.

The authors gratefully acknowledge support from the Ministry of Agriculture, Fisheries and Food, CEC Directorate-General for Agriculture, and F. Hoffmann-La Roche, Basle in carrying out this work. Also acknowledged is the fine technical assistance of Irene Alexander and Laura Dick.

\section{REFERENCES}

Cancela, L., Theofan, G. \& Norman, A. W. (1988). The pleiotropic vitamin D hormone. In Hormones and their Actions, Part 1, chpt. 15, [B. A. Cooke and H. J. van der Molen, editors]. Amsterdam: Elsevier Science Publishers BV (Biomedical Division).

Edwards, H. M. Jr (1987). Effects of thiuram, disulfiram and a trace element mixture on the incidence of tibial dyschondroplasia in chickens. Journal of Nutrition 117, 964-969.

Edwards, H. M. Jr (1989). The effect of dietary cholecalciferol, 25-hydroxycholecalciferol and 1,25dihydroxycholecalciferol on the development of tibial dyschondroplasia in broiler chickens in the absence and presence of disulfiram. Journal of Nutrition 119, 647-652.

Edwards, H. M. Jr (1990). Efficacy of several vitamin D compounds in the prevention of tibial dyschondroplasia in broiler chickens. Joumal of Nutrition 120, 1054-1061.

Edwards, H. M. Jr \& Veltmann, J. R. Jr (1983). The role of calcium and phosphorus in the etiology of tibial dyschondroplasia in young chicks. Journal of Nutrition 113, 1568-1575.

Farquarson, C., Whitehead, C. C., Rennie, J. S., Thorp, B. H. \& Loveridge, N. (1991). Cell proliferation and enzyme activities associated with the development of avian tibial dyschondroplasia: an in situ biochemical study. Bone 13, 59-67.

Gerstenfeld, L. C., Kelly, C. M., Von Deck, M. \& Lian, J. B. (1990). Effect of 1,25-dihydroxyvitamin $D_{3}$ on induction of chondrocyte maturation in culture: extracellular gene expression and morphology. Endocrinology 126, $1599-1609$.

Goff, J. P., Reinhardt, T. A., Beckman, M. J. \& Horst, R. L. (1990). Contrasting effects of exogenous 1,25dihydroxyvitamin $\mathrm{D}[1,25-(\mathrm{OH}) 2 \mathrm{D}]$ versus endogenous $1,25-(\mathrm{OH}) 2 \mathrm{D}$, induced by dietary calcium restriction, on vitamin D receptors. Endocrinology 126, 1031-1035.

Halley, J. T., Nelson, T. S., Kirby, L. K. \& Johnson, Z. B. (1987). Effect of altering dietary mineral balance on growth, leg abnormalities and blood base excess in broiler chicks. Poultry Science 66, 1684-1692.

Huff, W. E. (1980). Evaluation of tibial dyschondroplasia during aflatoxicosis and feed restriction in broiler chickens. Poultry Science 59, $991-995$.

Lacey, D. L. \& Huffer, W. E. (1982). Studies on the pathogenesis of avian rickets. 1. Changes in epiphyseal and metaphyseal vessels in hypocalcaemic and hypophosphataemic rickets. American Journal of Pathology 109 , $288-301$.

Leach, R. M. Jr \& Nesheim, M. (1965). Nutritional, genetic and morphological studies of an abnormal cartilage formation in young chicks. Journal of Nutrition $\mathbf{8 6}, 236-244$.

Leach, R. M. Jr \& Nesheim, M. (1972). Further studies on tibial dyschondroplasia (cartilage abnormality) in young chicks. Joumal of Nutrition 102, 1673-1680.

Lynch, M., Thorp, B. H. \& Whitehead, C. C. (1991). Avian tibial dyschondroplasia as a cause of bone deformity. Avian Pathology 21, 275-285.

Marx, S. J. (1989). Vitamin D and other calciferols. In The Metabolic Basis of Inherited Disease, 6th ed., chpt. 80 , [C. R. Scriver, A. L. Beaudet, W. S. Sly and D. Valle, editors]. New York: McGraw-Hill Information Services Company.

Riddell, C. \& Pass, D. A. (1987). The influence of dietary calcium and phosphorus on tibial dyschondroplasia in broiler chickens. Avian Diseases 31, 77 [-775.

Soares, J. H. Jr, Shellum, T. S. \& Kerr, J. M. (1990). Vitamin D receptor number and affinity in tibial dyschondroplasia. Journal of Bone and Mineral Research 5, Suppl. 2, S167.

Suda, S., Takahashi, N., Shinki, T., Horiuchi, N., Yoshida, S., Enomoto, S. \& Suda, T. (1985). 1 $\alpha, 25-$ dihydroxyvitamin $\mathrm{D}_{3}$ receptors and their action in embryonic chick chondrocytes. Calcified Tissue International 37, $82-90$.

Thorp, B. H. (1988). Relationship between the rate of longitudinal bone growth and physeal thickness in the growing fowl. Research in Veterinary Science 45, 83-85. 
Thorp, B. H., Whitehead, C. C. \& Rennie, J. S. (1991). Avian tibial dyschondroplasia: a comparison of the incidence and severity as assessed by gross examination and histopathology. Research in Veterinary Science 51, 48-54.

Vargas, M. I., Lamas, J. M. \& Alvarenga, V. (1983). Tibial dyschondroplasia in growing chickens experimentally intoxicated with tetramethylthiuram disulphide. Poultry Science 62, 1195-1200.

Veltmann, J. R. Jr, Rowland, G. N. \& Linton, S. S. (1985). Tibial dyschondroplasia in single-comb white leghorn chicks fed tetramethylthiuram disulphide (a fungicide). Avian Diseases 29, 1269-1272. 